\title{
Extra Ocular Muscle Fenestration as a Weakening Maneuver for Surgical Management of Strabismus: A Randomized Pilot Clinical Trial
}

\author{
Sameh G Taher' \\ Mahmoud A Rageh' \\ Omar Hashem ${ }^{2}$ \\ 'Department of Pediatric Ophthalmology \\ and Strabismus, Research Institute of \\ Ophthalmology, Giza, Egypt; \\ ${ }^{2}$ Department of Cornea and Refractive \\ Surgery, Research Institute of \\ Ophthalmology, Giza, Egypt
}

Purpose: This study aimed to evaluate the efficacy and safety of fenestration in comparison to the classic muscle recession as a weakening maneuver to horizontal and vertical extra ocular muscles in the surgical management of strabismus.

Patients and Methods: This is a pilot single blind parallel group randomized controlled trial with 1:1 allocation ratio. Male or female patients aged 1- to 60-years-old who were admitted to the Pediatric Ophthalmology and Strabismus Department for surgical correction of horizontal or vertical strabismus. Patients were randomly allocated by the envelop method to either group 1 (muscle fenestration, $\mathrm{N}=9$ ) or group 2 (classic muscle recession, $\mathrm{N}=9$ ). All participants were assessed at the first post operative day, at one week, and one month after the surgery for the outcomes.

Results: Postoperative ocular alignment evaluated at the first day, one week, and one month following the operation showed comparable results with no significant differences between both groups $(\mathrm{p}>0.05)$. The median postoperative pain score evaluated at the first day following the operation was significantly higher in fenestration group than recession group (the medians were 2.0 and 1.0, respectively, $\mathrm{p}=0.014$ ). Alternatively, the medians of the pain score were equal in both groups at one week and one month postoperatively $(p>0.999)$. One patient in the fenestration group developed progressive subconjunctival hemorrhage. In contrast, there was no postoperative complications in the recession group ( $p>0.999)$.

Conclusion: Efficacy and safety of muscle fenestration for correcting horizontal or vertical strabismus was comparable to the classic muscle recession.

Keywords: adults, children, fenestration, recession, strabismus, surgery

\section{Introduction}

Strabismus is one of the commonly encountered ophthalmologic diseases. It typically involves a lack of coordination between the extraocular muscles, where the eyes are lacking a proper alignment with each other. ${ }^{1}$

Surgical correction of strabismus should be considered after failure of conservative treatments. The aims of surgery are to restore proper ocular alignment, maintain binocular vision, eliminate diplopia, with the ultimate restoration of stereopsis. $^{2}$

Strabismus surgery includes weakening of the extra ocular muscle to decrease the effective strength of muscle action. Many weakening procedures have been described. Muscle recession is the standard and often most commonly used weakening technique. It involves disinserting the muscle from its original attachment and moving it posteriorly
Department of Cornea and Refractive Surgery, Research Institute of Ophthalmology, 2 El Ahram St, Giza, Egypt Tel +201 222422032

Email hashemomar@yahoo.com; omar.hashim004@gmail.com 
away from the limbus. ${ }^{3}$ Muscle recession may be associated with complications related to suturing and muscle disinsertion. ${ }^{4}$

Recently, extra ocular muscle fenestration has been reported as a new surgical technique for weakening of the extraocular muscles without using sutures or botulinum toxin. The fenestration technique reduces the muscle force by removing a block of the muscle close to its insertion which is done in between 2 peripheral muscle strips. It is a promising simple technique that might avoid the complications of using sutures such as foreign body reactions and granuloma formation. ${ }^{5}$

This study aimed to evaluate the efficacy and safety of fenestration in comparison to the classic muscle recession as a weakening maneuver to horizontal and vertical extra ocular muscles in the surgical management of strabismus.

\section{Materials and Methods}

\section{Ethical Considerations}

This study obtained approval of the Ethics Committee of the Research Institute of Ophthalmology, Cairo, Egypt, and it was conducted in accordance with the Declaration of Helsinki. A written informed consent was taken from each patient or his/her guardians (if the patient was unable to participate in the consent process). Confidentiality of the data was maintained by making code numbers for each patient. The trial was registered at the Iranian Registry of Clinical Trials (IRCT20200503047293N1; 20-5-2020).

\section{Study Design, Settings, and Date}

This is a pilot, single-blind, parallel-group, randomized, controlled trial with 1:1 allocation ratio. It was carried out at the Research Institute of Ophthalmology, Egypt during May to July 2020.

\section{Inclusion Criteria}

Male or female patients aged 1- to 60-years-old who were admitted to the Pediatric Ophthalmology and Strabismus Department for surgical correction of horizontal or vertical strabismus. Diagnosis was made after complete routine ophthalmological evaluation, followed by evaluating the angle of strabismus and deciding the amount of the needed muscle weakening.

\section{Exclusion Criteria}

Patients with previous strabismus surgery upon the target muscle to be weakened, previous orbital surgery, orbital masses, or orbital inflammatory diseases were excluded.

\section{Interventions}

Patients were randomly allocated by the envelop method to either group 1 (muscle fenestration) or group 2 (classic muscle recession) as follows:

Group 1 (muscle fenestration): The rectus muscle was exposed through a fornix conjunctival incision, then the muscle was stretched between 2 muscle hooks, and 2 peripheral muscle strips each $1 \mathrm{~mm}$ in width was created using a fine muscle hook or by stripping the muscle fibers with a silk suture starting proximal at the desired site till the muscle insertion. Then, the 2 muscle strips were separated on each side and the muscle belly in between was excised leaving a bare sclera (a fenestration or a window defect). The conjunctiva was re-positioned, and the surgery was concluded.

Group 2 (classic muscle recession): The muscle was exposed by fornix incision. Dissection of the conjunctiva and tenon capsule was done. Hooking of the muscle by Jameson hook and dissection of the intermuscular septum was done. A Chavasse muscle hook was exchanged with Jameson muscle hook, and the muscle was secured with a coated double-armed Vicryl 6-0 suture with an s-29 needle. The desired amount of recession was measured from the original insertion by a caliper. Scleral sutures were taken at the superior and inferior edges parallel to the original insertion. The muscle was pulled up to the level of the desired new insertion, making sure the sutures are taut and the muscle belly spreads nicely against the sclera. A knot was tied with a double forehand throw, a single backhand throw, and a final single forehand throw. The sutures were cut $2 \mathrm{~mm}$ from knot. The conjunctiva was then closed with 2 interrupted Vicryl 8-0 sutures (Figure 1).

\section{Outcome Measure}

The following primary and secondary outcomes were assessed at the first post operative day, at one week, and at one month after the surgery.

\section{Primary Outcome}

Ocular alignment or balance assessed by corneal light reflex, Krimisky test, and prism cover test.

\section{Secondary Outcomes}

1. Ocular motility described as free versus limited motility. It was assessed by versions and ductions.

2. Post-operative pain assessed by asking the patient about postoperative pain and grading it on pain score from 1 to 5 . 


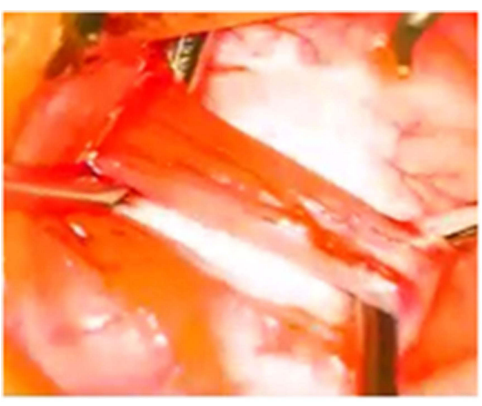

1. Exposure of the medial rectus through a fornix incision

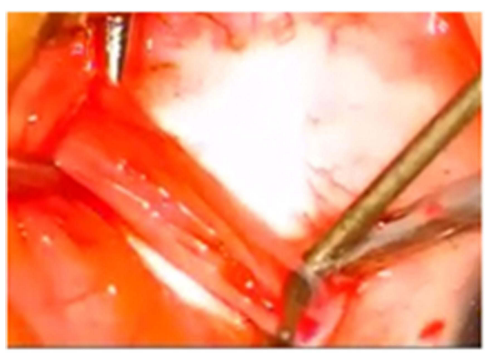

\section{Separation of $1 \mathrm{~mm}$ strip}

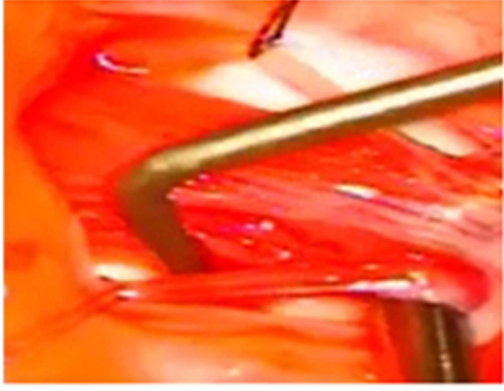

3. Separation of $1 \mathrm{~mm}$ strip on the other edge

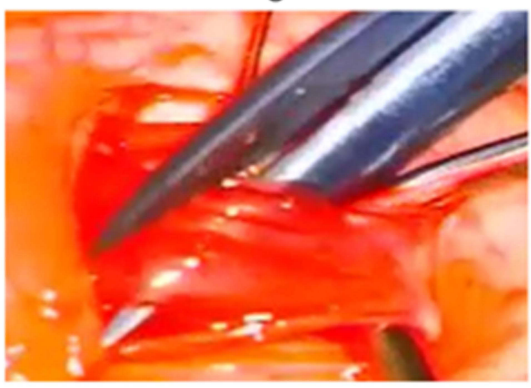

4. Bloc excision

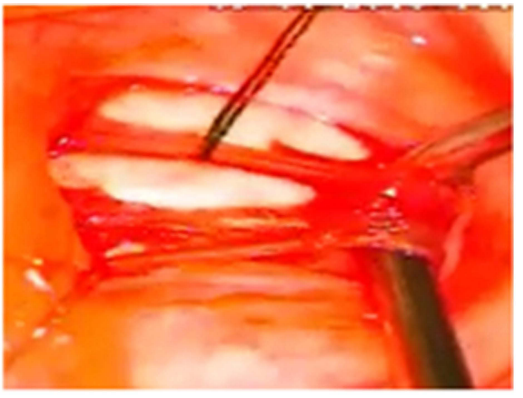

5. The muscle after fenestration

Figure I Muscle fenestration technique.

Patients were also monitored for adverse effects of operation including subconjunctival hemorrhage, muscle dehiscence or slippage, and cut or torn muscle horns. A detailed documentation of any adverse effect and its management was undertaken.

\section{Statistical Analysis}

Statistical analysis was performed using the Statistical Package for Social Sciences (IBM SPSS Statistics) for Windows, version 26 (IBM Corp., Armonk, N.Y., USA). Continuous data were tested for normality by the ShapiroWilk test. Data were not normally distributed and were presented as the median and interquartile range (25th-75th percentiles) and the Mann-Whitney $U$-test was applied for comparison between the groups. Categorical data were presented as numbers and frequencies and Fisher's Exact test was applied for associations between variables. P-value less than 0.05 was considered statistically significant.

\section{Results}

This pilot, randomized, controlled, trial included 18 patients who were admitted for surgical correction of horizontal or vertical strabismus during May to July 2020. They were randomly allocated into either group 1 (fenestration group, $\mathrm{N}=9$ ) or group 2 (recession group, $\mathrm{N}=9$ ). The patients in both groups completed their follow-up at the designed time intervals including the first day, one week, and one month following the operation (Figure 2).

There were homogenous distributions of the age and gender of the patients among the studied groups with no significant differences $(\mathrm{p}>0.05)$ (Table 1$)$.

Postoperative ocular alignment evaluated at the first day, one week, and one month following the operation showed comparable results with no significant differences between both groups $(\mathrm{p}>0.05)$. At the first postoperative day, $4(44.4 \%)$ patients in the fenestration group showed orthotropic ocular alignment compared to 6 $(66.7 \%)$ patients in the recession group $(\mathrm{p}=0.158)$. Followup at one week and one month revealed frequency of orthotropic alignment of $44.4 \%$ and $88.9 \%$ in both groups, with no significant differences (Table 2).

Assessment of ocular motility at the first day, one week, and one month following the operation in the studied groups is shown in Table 3. At the first postoperative day, the frequency of free ocular motility was significantly higher in the fenestration group (77.8\%) compared to the recession group (22.2\%). At one week after the operation, free motility was detected in $8(88.9 \%)$ patients in fenestration group and $7(77.8 \%)$ patients in 


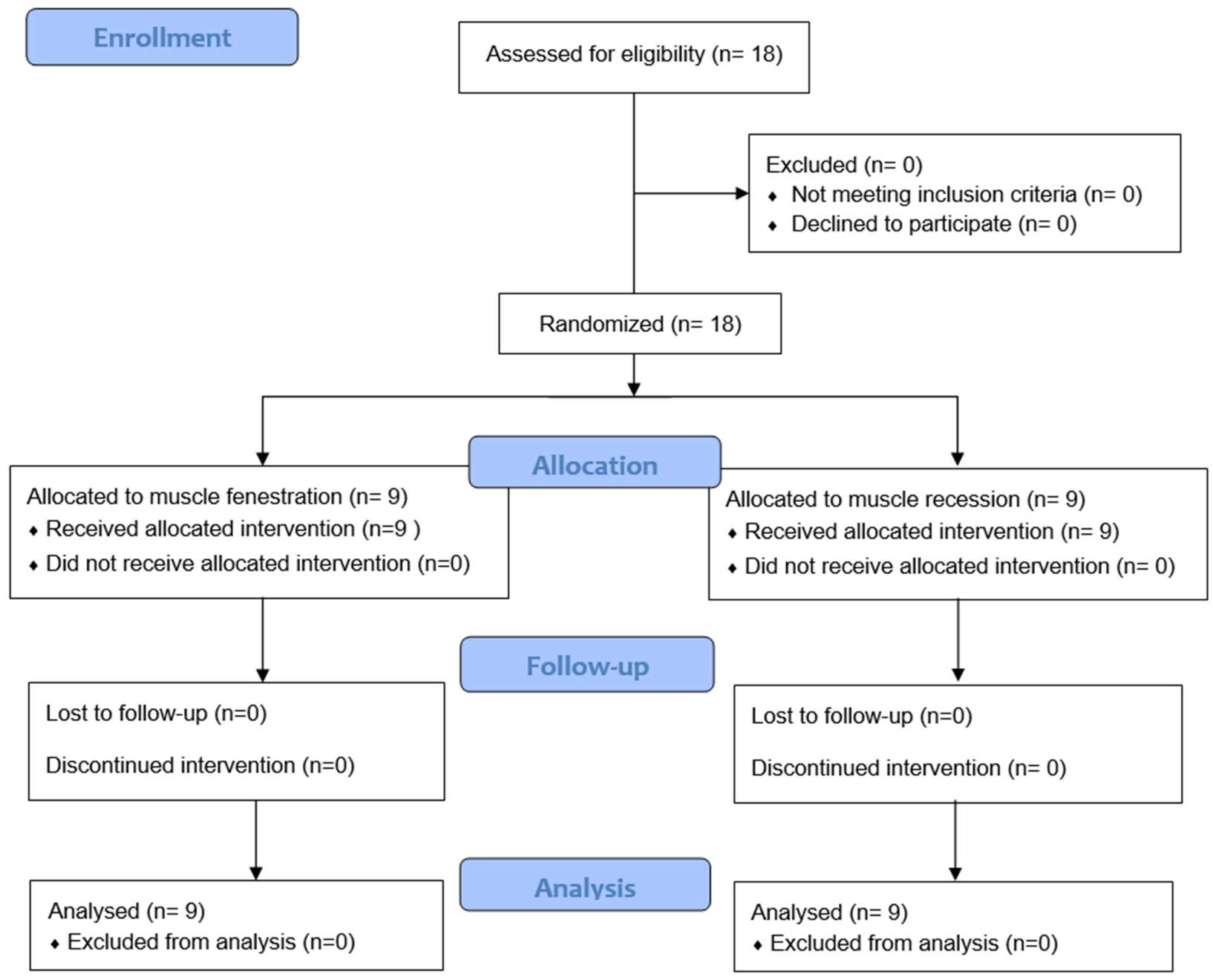

Figure 2 The trial flow diagram.

recession group with no significant difference ( $p>0.999)$. At one month, the frequency of free motility was equal in both groups $(88.9 \%$ each).

The median postoperative pain score evaluated at the first day following the operation was significantly higher in fenestration group than recession group (the medians were 2.0 and 1.0 , respectively, $\mathrm{p}=0.014$ ). Alternatively, the medians of the pain score were equal in both groups at one week and one month postoperatively ( $p>0.999)$ (Table 4).

The results of this study revealed under-correction in 2 patients in the fenestration group compared to 1 patient in the recession group. Further, 2 patients in the fenestration group showed failure of correction (esotropia $40 \mathrm{PD}$ ) with no significant difference between both groups $(\mathrm{p}=0.356)$ (Table 5).

Monitoring of the patients in both groups for adverse effects revealed that one patient in the fenestration group developed progressive subconjunctival hemorrhage and was readmitted $2 \mathrm{~h}$ after the surgery for exploration where cautery of bleeding small vessels was done, and on the 2nd postoperative day there was mild resolving subconjunctival hemorrhage. In contrast, there were no postoperative complications in the recession group $(\mathrm{p}>0.999)$ (Table 6). None of the patients in both groups developed muscle dehiscence or slippage, cut or torn muscle horns.

\section{Discussion}

Strabismus is a common disorder that negatively affect vision as well as life quality. ${ }^{6}$ Successful strabismus surgery has many functional and psychological benefits. In children, strabismus correction has been associated with measurable improvement in the children and parents' quality of life. ${ }^{7}$ There is a continuous need for sutureless surgery with less surgical manipulations, while achieving the same results obtained by conventional surgery. ${ }^{8}$ 
Table I Demographic Characteristics of the Studied Groups

\begin{tabular}{|c|c|c|c|c|c|}
\hline & & & \multicolumn{2}{|c|}{ Groups } & \multirow[t]{2}{*}{$P$ value } \\
\hline & & & $\begin{array}{c}\text { Group I } \\
\text { Fenestration } \\
\quad \mathrm{N}=9\end{array}$ & $\begin{array}{c}\text { Group } 2 \\
\text { Recession } \\
\mathbf{N}=9\end{array}$ & \\
\hline \multirow{3}{*}{$\begin{array}{l}\text { Age } \\
\text { (years) }\end{array}$} & \multicolumn{2}{|c|}{ Minimum-Maximum } & $2.0-34.0$ & $1.0-40.0$ & \multirow[t]{3}{*}{0.297} \\
\hline & \multicolumn{2}{|l|}{ Median } & 4.0 & 15.0 & \\
\hline & \multicolumn{2}{|l|}{ IQR } & $4.0-14.0$ & $10.0-30.0$ & \\
\hline \multirow[t]{4}{*}{ Sex } & \multirow[t]{2}{*}{ Female } & $\mathrm{N}$ & 2 & 3 & \multirow[t]{4}{*}{$>0.999$} \\
\hline & & $\%$ & $22.2 \%$ & $33.3 \%$ & \\
\hline & \multirow[t]{2}{*}{ Male } & $\mathrm{N}$ & 7 & 6 & \\
\hline & & $\%$ & $77.8 \%$ & $66.7 \%$ & \\
\hline
\end{tabular}

Abbreviations: IQR, interquartile range; $\mathrm{N}$, number.
The present pilot randomized controlled trial demonstrated comparable efficacy and safety of muscle fenestration and classic muscle recession for restoring ocular alignment after correcting horizontal or vertical strabismus.

Assessment of ocular balance at the first postoperative day showed orthotropia in 4 (44.4\%) patients belonging to the fenestration group compared to $6(66.7 \%)$ patients in the recession group with no significant differences. Follow-up at one week and one month also revealed similar frequency of orthotropic alignment of $44.4 \%$ and $88.9 \%$ in both groups. At the last follow up (one month after the surgery), 5 (55.6\%) and $8(88.9 \%)$ patients were corrected in the fenestration and recession groups respectively. Under-correction was recorded in 2 patients (Esotropia 10 and 15 PD) in the fenestration group

Table 2 Comparison Between the Studied Groups Regarding Postoperative Ocular Alignment Evaluated at the First Day, One Week, and One Month Following the Operation

\begin{tabular}{|c|c|c|c|c|c|c|}
\hline & & \multicolumn{4}{|c|}{ Groups } & \multirow{3}{*}{$\begin{array}{c}\text { Fisher's } \\
\text { Exact test } \\
\text { P value }\end{array}$} \\
\hline & & \multicolumn{2}{|c|}{$\begin{array}{c}\text { Group I } \\
\text { Fenestration } \\
\mathbf{N}=\mathbf{9}\end{array}$} & \multicolumn{2}{|c|}{$\begin{array}{c}\text { Group } 2 \\
\text { Recession } \\
\mathbf{N}=9\end{array}$} & \\
\hline & & $\mathbf{N}$ & $\%$ & $\mathbf{N}$ & $\%$ & \\
\hline \multirow[t]{7}{*}{ At the first day } & Esophoria & 0 & $0.0 \%$ & 1 & $11.1 \%$ & \multirow[t]{7}{*}{0.158} \\
\hline & Esotropia 35 PD & 0 & $0.0 \%$ & 1 & $11.1 \%$ & \\
\hline & Esotropia 40 PD & 2 & $22.2 \%$ & 0 & $0.0 \%$ & \\
\hline & Exophoria & 0 & $0.0 \%$ & 1 & $11.1 \%$ & \\
\hline & Orthotropic with glasses & 1 & $11.1 \%$ & 0 & $0.0 \%$ & \\
\hline & Orthotropic & 4 & $44.4 \%$ & 6 & $66.7 \%$ & \\
\hline & Esotropia 15 PD & 2 & $22.2 \%$ & 0 & $0.0 \%$ & \\
\hline \multirow[t]{5}{*}{ At one week } & Esotropia 30 PD & 0 & $0.0 \%$ & 1 & $11.1 \%$ & \multirow[t]{5}{*}{0.050} \\
\hline & Esotropia 40 PD & 2 & $22.2 \%$ & 0 & $0.0 \%$ & \\
\hline & Orthotropic with glasses & 1 & $11.1 \%$ & 0 & $0.0 \%$ & \\
\hline & Orthotropic & 4 & $44.4 \%$ & 8 & $88.9 \%$ & \\
\hline & Esotropia 15 PD & 2 & $22.2 \%$ & 0 & $0.0 \%$ & \\
\hline \multirow[t]{6}{*}{ At one month } & Esotropia 30 PD & 0 & $0.0 \%$ & 1 & $11.1 \%$ & \multirow[t]{6}{*}{0.090} \\
\hline & Esotropia 40 PD & 2 & $22.2 \%$ & 0 & $0.0 \%$ & \\
\hline & Orthotropic with glasses & 1 & $11.1 \%$ & 0 & $0.0 \%$ & \\
\hline & Orthotropic & 4 & $44.4 \%$ & 8 & $88.9 \%$ & \\
\hline & Esotropia 10 PD & 1 & $11.1 \%$ & 0 & $0.0 \%$ & \\
\hline & Esotropia 15 PD & 1 & $11.1 \%$ & 0 & $0.0 \%$ & \\
\hline
\end{tabular}

Abbreviations: PD, prism diopters; $\mathrm{N}$, number. 
Table 3 Assessment of Ocular Motility at the First Day, One Week, and One Month Following the Operation in the Studied Groups

\begin{tabular}{|c|c|c|c|c|c|c|}
\hline & & \multicolumn{4}{|c|}{ Groups } & \multirow{3}{*}{$\begin{array}{c}\text { Fisher's Exact test } \\
\text { P value }\end{array}$} \\
\hline & & \multicolumn{2}{|c|}{$\begin{array}{c}\text { Group I } \\
\text { Fenestration } \\
\mathbf{N}=9\end{array}$} & \multicolumn{2}{|c|}{$\begin{array}{c}\text { Group } 2 \\
\text { Recession } \\
\mathbf{N}=9\end{array}$} & \\
\hline & & $\mathbf{N}$ & $\%$ & $\mathbf{N}$ & $\%$ & \\
\hline \multirow[t]{8}{*}{ At the first day } & Bilaterally limited abduction-2 & 0 & $0.0 \%$ & 1 & $11.1 \%$ & \multirow[t]{8}{*}{$0.026 *$} \\
\hline & Limited abduction and adduction-I & 1 & $11.1 \%$ & 0 & $0.0 \%$ & \\
\hline & Limited abduction and adduction-IBE & 0 & $0.0 \%$ & 3 & $33.3 \%$ & \\
\hline & Limited abduction and adduction-2LE & 0 & $0.0 \%$ & 1 & $11.1 \%$ & \\
\hline & Limited abduction-ILE & 0 & $0.0 \%$ & 1 & $11.1 \%$ & \\
\hline & Limited abduction-IRE & 0 & $0.0 \%$ & I & $11.1 \%$ & \\
\hline & Minimally limited abduction $0.5 \mathrm{RE}$ & 1 & $11.1 \%$ & 0 & $0.0 \%$ & \\
\hline & Free & 7 & $77.8 \%$ & 2 & $22.2 \%$ & \\
\hline \multirow[t]{4}{*}{ At one week } & Bilaterally limited abduction-2 & 0 & $0.0 \%$ & I & $11.1 \%$ & \multirow[t]{4}{*}{$>0.999$} \\
\hline & Limited abduction and adduction-I LE & 0 & $0.0 \%$ & 1 & $11.1 \%$ & \\
\hline & Minimally limited abduction $0.5 \mathrm{RE}$ & 1 & $11.1 \%$ & 0 & $0.0 \%$ & \\
\hline & Free & 8 & $88.9 \%$ & 7 & $77.8 \%$ & \\
\hline \multirow[t]{3}{*}{ At one month } & Bilaterally limited abduction-2 & 0 & $0.0 \%$ & 1 & $11.1 \%$ & \multirow[t]{3}{*}{$>0.999$} \\
\hline & Minimally limited abduction $0.5 \mathrm{RE}$ & 1 & $11.1 \%$ & 0 & $0.0 \%$ & \\
\hline & Free & 8 & $88.9 \%$ & 8 & $88.9 \%$ & \\
\hline
\end{tabular}

Note: *Significant at $\mathrm{p}<0.05$.

Table 4 Postoperative Pain Score at the First Day, One Week, and One Month Time Points

\begin{tabular}{|c|c|c|c|c|}
\hline & & \multicolumn{2}{|c|}{ Groups } & \multirow[t]{2}{*}{$P$ value } \\
\hline & & $\begin{array}{c}\text { Group I } \\
\text { Fenestration } \\
\qquad \mathbf{N}=9\end{array}$ & $\begin{array}{c}\text { Group } 2 \\
\text { Recession } \\
\mathbf{N}=9\end{array}$ & \\
\hline \multirow{3}{*}{$\begin{array}{l}\text { At the } \\
\text { first day }\end{array}$} & Median & 2.0 & 1.0 & \multirow[t]{3}{*}{$0.014 *$} \\
\hline & IQR & $2.0-2.0$ & $1.0-2.0$ & \\
\hline & Mean rank & 12.5 & 6.5 & \\
\hline \multirow{3}{*}{$\begin{array}{l}\text { At one } \\
\text { week }\end{array}$} & Median & 1.0 & 1.0 & \multirow[t]{3}{*}{$>0.999$} \\
\hline & IQR & $1.0-1.0$ & $1.0-1.0$ & \\
\hline & Mean rank & 9.5 & 9.5 & \\
\hline \multirow{3}{*}{$\begin{array}{l}\text { At one } \\
\text { month }\end{array}$} & Median & 0.0 & 0.0 & \multirow[t]{3}{*}{$>0.999$} \\
\hline & IQR & $0.0-0.0$ & $0.0-0.0$ & \\
\hline & Mean rank & 9.5 & 9.5 & \\
\hline
\end{tabular}

Note: *Significant at $p<0.05$.

Abbreviations: IQR, interquartile range; $N$, number. compared to 1 patient (Esotropia $30 \mathrm{PD}$ ) in the recession group. Further, 2 patients in the fenestration group showed failure of correction (esotropia $40 \mathrm{PD}$ ). One of these patients was reoperated after 1 month by bilateral classic medial rectus $5 \mathrm{~mm}$ recession technique, and his follow up revealed orthotropia. Unfortunately, the other patient was lost. Furthermore, free muscle motility was significantly higher in the fenestration

Table 5 Postoperative Ocular Balance in the Studied Groups

\begin{tabular}{|c|c|c|c|c|}
\hline & & \multicolumn{2}{|c|}{ Groups } & \multirow[t]{2}{*}{$P$ value } \\
\hline & & $\begin{array}{c}\text { Group I } \\
\text { Fenestration } \\
\mathbf{N}=9\end{array}$ & $\begin{array}{c}\text { Group } 2 \\
\text { Recession } \\
\mathbf{N}=9\end{array}$ & \\
\hline \multirow{3}{*}{$\begin{array}{l}\text { Ocular } \\
\text { balance status } \\
\text { at the last } \\
\text { follow-up }\end{array}$} & Corrected & $5(55.6 \%)$ & 8 (88.9\%) & \multirow[t]{3}{*}{0.356} \\
\hline & Not corrected & $2(22.2 \%)$ & $0(0.0 \%)$ & \\
\hline & Under corrected & $2(22.2 \%)$ & I (II.1\%) & \\
\hline
\end{tabular}

Abbreviation: $\mathrm{N}$, number. 
Table 6 Postoperative Complications in the Studied Groups

\begin{tabular}{|l|l|l|c|c|c|}
\hline \multicolumn{2}{|c|}{} & \multicolumn{2}{c|}{ Proups } & \multirow{2}{*}{ value } \\
\cline { 2 - 5 } & $\begin{array}{c}\text { Group I } \\
\text { Fenestration } \\
\text { N=9 }\end{array}$ & $\begin{array}{c}\text { Group 2 } \\
\text { Recession } \\
\text { N=9 }\end{array}$ & \\
\hline $\begin{array}{l}\text { Complications } \\
\text { (Progressive } \\
\text { subconjunctival } \\
\text { hemorrhage) }\end{array}$ & No & N & 8 & 9 & \multirow{2}{*}{$>0.999$} \\
\cline { 2 - 5 } & Yes & N & 1 & 0 & \\
\cline { 2 - 5 } & $\%$ & $11.1 \%$ & $0.0 \%$ & \\
\hline
\end{tabular}

Abbreviation: N, number.

group than the recession group at the first postoperative follow up, but later the two techniques were comparable regarding the frequency of free muscle motility.

Currently, there is no standard uniform definition for successful outcomes of strabismus surgery. There is no consensus on the sufficient length of time after surgery to consider outcomes stable. As well, there is no agreement on the magnitude of deviation that can be considered success. Therefore, comparison between different treatment approaches from different studies cannot be efficiently performed. ${ }^{9}$

A previous descriptive study assessed the outcome of muscle fenestration in cases of strabismus with a mean age of 16.3 years and a median follow up period of 3 months. The authors documented ocular alignment with 8 PD in 12 out of 13 cases of esotropia and in 3 out of 5 cases of exotropia. There were further 3 cases with dissociated vertical deviation who showed reduction of deviation to less than 6 PD. The fenestration technique was successful in correcting the deviations and was also safe with no recorded overcorrection, limitation of ocular motility, intraoperative or postoperative complications. ${ }^{5}$

Another study evaluated the effectiveness and the safety of fenestration technique of the medial recuts muscle combined with resection of ipsilateral lateral rectus muscle in 16 children with sensory esotropia. There was satisfactory postoperative ocular alignment, within 8 PD of orthotropia at distance in $81.25 \%$ of the cases at 3 months of follow-up. There were no overcorrections or adverse effects. ${ }^{10}$

Pain after strabismus surgery can cause emotional distress to both patients and parents and can result in poor family satisfaction and delayed discharge from hospital. The mean monthly incidence of moderate to severe postoperative pain following pediatric strabismus surgery was $47.3 \%$ as reported by Ali et al. ${ }^{11}$ An earlier study reported the incidence of clinically significant pain to be as high as $65 \% .{ }^{12}$ In the present study, muscle fenestration technique was more significantly painful at the first day following the operation. However, assessment of pain score at one week and one month after the surgery showed equal results.

Fenestration technique involves removal of part of the muscle close to its insertion which might carry a risk of bleeding. Using diathermy to mark the excision site can diminish this bleeding. ${ }^{5}$ In this regard, one patient in the fenestration group developed progressive subconjunctival hemorrhage. The patient was successfully managed by cautery of bleeding small vessels after readmission and exploration.

Although there is a possible risk of muscle slippage in the fenestration technique because the muscle is left with only limited attachment to the sclera, there was no recorded muscle dehiscence or slippage in either group in the present study.

Given the comparable efficacy and safety of the fenestration and classic recession here in, there are clear advantages of the fenestration technique over the classic recession, namely, easy surgical procedure and being entirely sutureless. Lack of suturing reduces the risk of scleral perforation which is a possible major complication with any procedure involves partial thickness scleral suture. ${ }^{13}$

This study is limited by small sample size and short period of follow up.

\section{Conclusion}

This pilot randomized controlled trial gave a preliminary data on the outcomes of the novel muscle weakening fenestration technique in strabismus surgery. Efficacy and safety of muscle fenestration for correcting horizontal or vertical strabismus was comparable to the classic muscle recession. Though safe, one case out of 9 had immediate post-operative subconjunctival hemorrhage that was properly managed with no consequent dangerous complications. Further randomized controlled trials based on sample size calculation, besides evaluating the outcomes in subgroups of strabismus types are recommended before generalization of these findings as this may show higher percentage of complications. As well, longer periods of follow up for evaluating the long-term efficacy and safety should be considered. 


\section{Data Sharing Statement}

We intend to share the individual de-identified participants' data. Data will be accessible on reasonable request through direct contact with the corresponding author, beginning 12 months and ending 24 months following article publication.

\section{Disclosure}

The authors report no conflicts of interest in this work.

\section{References}

1. Gunton KB, Wasserman BN, DeBenedictis C. Strabismus. Prim Care. 2015;42(3):393-407. doi:10.1016/j.pop.2015.05.006

2. Sharma P, Gaur N, Phuljhele S, Saxena R. What's new for us in strabismus? Indian J Ophthalmol. 2017;65(3):184-190. doi:10.4103/ ijo.IJO $867 \quad 16$

3. Jain S. Surgical and non-surgical treatment of strabismus. In: Jain S, editor. Simplifying Strabismus: A Practical Approach to Diagnosis and Management. Cham: Springer International Publishing; 2019:159-174.

4. Wan MJ, Hunter DG. Complications of strabismus surgery: incidence and risk factors. Semin Ophthalmol. 2014;29(5-6):421-428. doi:10.3109/08820538.2014.959190

5. Rageh MA, Awadein A, Arfeen SA. Extraocular muscle fenestration: a novel weakening procedure. Can $J$ Ophthalmol. 2020;55 (5):455-457. doi:10.1016/j.jcjo.2020.05.018
6. Zheng Y, Fu H, Li R, et al. Intelligent evaluation of strabismus in videos based on an automated cover test. Appl Sci. 2019;9(4):731. doi:10.3390/app9040731

7. Holmes JM, Hercinovic A, Melia BM, et al. Improvement in health-related quality of life following strabismus surgery for children with intermittent exotropia. J AAPOS. 2021;25(2):82. e81-82.e87.

8. Jang KH, Kong M, Moon BG, Son G. Comparison of scleral fixation of intraocular lens: sutureless intrascleral fixation versus conventional sutured scleral fixation. Retina. 2021;41(4):761-767. doi:10.1097/ IAE.0000000000002952

9. Serafino M, Granet DB, Kushner BJ, et al. Definition of successful outcomes after surgery for each type of strabismus: a Delphi study. J AAPOS. 2021;25(1):3.e1-3.e5. doi:10.1016/j.jaapos.2020.08.014

10. Elkhawaga MH, Elshakankiri NM, Helaly HA, Elkamshoushy AA. Evaluation of fenestration technique of the medial recuts muscle with resection of ipsilateral lateral rectus muscle in patients with sensory esotropia. J Egypt Ophthalmol Soc. 2020;113(4):142. doi:10.4103/ ejos.ejos_28_20

11. Ali U, Tsang M, Campbell F, et al. Reducing postoperative pain in children undergoing strabismus surgery: from bundle implementation to clinical decision support tools. Paediatr Anaesth. 2020;30 (4):415-423. doi:10.1111/pan.13811

12. Finley AG, McGrath PJ, Forward PS, McNeill G, Fitzgerald P. Parents' management of children's pain following 'minor' surgery. Pain. 1996;64(1):83-87. doi:10.1016/0304-3959(95)00091-7

13. Park K, Hong S, Chung W, et al. Inadvertent scleral perforation after strabismus surgery: incidence and association with refractive error. Can J Ophthalmol. 2008;43(6):669-672. doi:10.3129/i08-151
Clinical Ophthalmology

\section{Publish your work in this journal}

Clinical Ophthalmology is an international, peer-reviewed journal covering all subspecialties within ophthalmology. Key topics include: Optometry; Visual science; Pharmacology and drug therapy in eye diseases; Basic Sciences; Primary and Secondary eye care; Patient Safety and Quality of Care Improvements. This journal is indexed on PubMed

\section{Dovepress}

Central and CAS, and is the official journal of The Society of Clinical Ophthalmology (SCO). The manuscript management system is completely online and includes a very quick and fair peer-review system, which is all easy to use. Visit http://www.dovepress.com/ testimonials.php to read real quotes from published authors. 